\title{
Cerebrospinal Fluid Biomarkers Predict Gait Outcomes in Idiopathic Normal Pressure Hydrocephalus
}

\section{Author(s):}

Jacqueline A. Darrow, MS ${ }^{1}$; Alexandria Lewis, $\mathrm{BS}^{1}$; Seema Gulyani, $\mathrm{PhD}^{1}$; Kristina Khingelova, PA-C ${ }^{1}$; Aruna Rao, $\mathrm{MD}^{1}$; Jiangxia Wang, $\mathrm{MS}^{2}$; Yifan Zhang, $\mathrm{MS}^{2}$; Mark Luciano, $\mathrm{MD}^{3}$; Sevil Yasar, $\mathrm{MD}^{4}$; Abhay Moghekar, MB,BS ${ }^{1}$

\section{Equal Author Contributions:}

Jacqueline A. Darrow and Alexandria Lewis are co-first authors

This is an open access article distributed under the terms of the Creative Commons Attribution-NonCommercial-NoDerivatives License 4.0 (CC BY-NC-ND), which permits downloading and sharing the work provided it is properly cited. The work cannot be changed in any way or used commercially without permission from the journal.

Neurology® Clinical Practice Published Ahead of Print articles have been peer reviewed and accepted for publication. This manuscript will be published in its final form after copyediting, page composition, and review of proofs. Errors that could affect the content may be corrected during these processes. 


\section{Corresponding Author:}

Abhay Moghekar

amogheka@jhmi.edu

Affiliation Information for All Authors: 1. Department of Neurology, Johns Hopkins University School of Medicine, Baltimore, MD, USA; 2. Department of Biostatistics, Johns Hopkins University Bloomberg School of Public Health, Baltimore, MD, USA; 3. Department of Neurosurgery, Johns Hopkins University School of Medicine, Baltimore, MD, USA; 4. Department of Medicine, Johns Hopkins University School of Medicine, Baltimore, MD, USA;

\section{Contributions:}

Jacqueline A. Darrow: Drafting/revision of the manuscript for content, including medical writing for content; Major role in the acquisition of data; Study concept or design; Analysis or interpretation of data; Additional contributions: Study concept or design, interpretation of the data, drafted and revised the manuscript for content, study supervision and coordination

Alexandria Lewis: Drafting/revision of the manuscript for content, including medical writing for content; Major role in the acquisition of data; Study concept or design; Analysis or interpretation of data; Additional contributions: Study concept or design, interpretation of the data, drafted and revised the manuscript for content, study supervision and coordination

Seema Gulyani: Study concept or design; Additional contributions: Study supervision and coordination Kristina Khingelova: Study concept or design; Additional contributions: Study supervision and coordination

Aruna Rao: Study concept or design; Additional contributions: Study supervision and coordination Jiangxia Wang: Drafting/revision of the manuscript for content, including medical writing for content; Analysis or interpretation of data; Additional contributions: Performed the statistical analyses, interpretation of the data, revised the manuscript for content

Yifan Zhang: Drafting/revision of the manuscript for content, including medical writing for content; Analysis or interpretation of data; Additional contributions: Performed the statistical analyses, interpretation of the data, revised the manuscript for content

Mark Luciano: Major role in the acquisition of data; Additional contributions: Study supervision and coordination

Sevil Yasar: Major role in the acquisition of data; Additional contributions: Study supervision and coordination

Abhay Moghekar: Drafting/revision of the manuscript for content, including medical writing for content; Major role in the acquisition of data; Study concept or design; Analysis or interpretation of data; Additional contributions: Supervised the analysis ofCSF, study concept or design, interpretation of the data, drafted and revised the manuscript for content, study supervision and coordination

Number of characters in title: 96

Abstract Word count: 250

Word count of main text: 4027

References: 50

Figures: 4

Tables: 3 
Statistical Analysis performed by: Jiangxia Wang, MS and Yifan Zhang, MS Department of Biostatistics, Johns Hopkins University Bloomberg School of Public Health, Baltimore, MD, USA

Search Terms: [ 319 ] Spinal cord infection

Acknowledgements: The authors thank Dr. Marilyn Albert, who provided expertise and guidance regarding drafting the manuscript and subtantive editing help. The authors would also like the thank the Lantry Family Foundation and the Myers Family for their philanthropic contributions toward this research project.

Study Funding: Lantry Family Foundation and the Myers Family.

Disclosures: J. A. Darrow reports no disclosures relevant to the manuscript; A. Lewis reports no disclosures relevant to the manuscript; S. Gulyani reports no disclosures relevant to the manuscript; K. Khingelova reports no disclosures relevant to the manuscript; A. Rao reports no disclosures releyant to the manuscript; J. Wang reports no disclosures relevant to the manuscript; Y. Zhang reports no disclosures relevant to the manuscript; M. Luciano reports no disclosures relevant to the manuscript; S. Yasar reports no disclosures relevant to the manuscript; A. Moghekar reports research support from Fujirebio Diagnostics Ltd.

\section{ABSTRACT}

\section{Objective:}

The assessment of biomarkers in selecting idiopathic normal pressure hydrocephalus (iNPH)

patients for shunt surgery has been limited to small cohort studies and those with limited followup. We assessed the potential for cerebrospinal fluid (CSF) biomarkers in predicting immediate response to CSF tap test (TT) and long-term response after shunt surgery.

Methods: CSF was obtained from iNPH patients referred for CSF TT after baseline assessment of cognition and gait. CSF neurofilament-light (NFL), $\beta$-amyloid-42 (A $\left.\beta_{1-42}\right), \beta$-amyloid-40 $\left(\mathrm{A} \beta_{1-40}\right)$, total tau (t-Tau), and phosphorylated-tau-181(pTau181) and leucine-rich-alpha-2glycoprotein1 (LRG1) were measured by ELISA. The ability of these measures to predict 
immediate improvement following CSF TT and long-term improvement following shunt surgery was compared by univariate and adjusted multivariate regression.

Results: Lower NFL, pTau181, tTau and $\mathrm{A} \beta_{1-40}$ were individually predictive of long-term improvement in gait outcomes after shunt surgery. A multivariate model of these biomarkers and MRI Evan's index, adjusted for age, improved prediction (AUC-ROC: 0.76, (95\% CI [0.66, 0.86]). tTau, pTau181 and $A \beta_{1-40}$ levels were statistically different in those whose gait improved after CSF TT compared to those who did not. Using a multivariate model, combining these markers with Evan's index and transependymal flow did not significantly improve prediction of an immediate response to CSF TT.

Conclusion: A combination of CSF biomarkers can predict improvement following shunt surgery for iNPH. However, these measures only modestly discriminate responders from nonresponders following CSF TT. The findings further suggest that abnormal CSF biomarkers in non-responders may represent comorbid neurodegenerative pathology or a pre-degenerative phase that presents with an iNPH phenotype.

\section{INTRODUCTION}

Idiopathic normal-pressure hydrocephalus (iNPH) is a putative reversible neurodegenerative disorder that is one of the few treatable causes of cognitive and gait impairment in the elderly. ${ }^{1}$ However, differentiating iNPH from other age-related neurological disorders is complex., ${ }^{2,3}$ Moreover, shunts are associated with a high adverse event rate of approximately $11 \%$, including infection, malfunction, additional surgery, and subdural hematomas. ${ }^{4-6}$ Hence specific biomarkers that could differentiate iNPH from other disorders and predict improvement after shunt surgery would be beneficial by ensuring accurate diagnosis and could potentially improve the prediction of shunt response. ${ }^{7-9}$

A meta-analysis by Pfanner and colleagues, concluded that $\beta$-amyloid-protein-42 (A $\beta_{1-}$ 42), total-tau (tTau), phosphorylated-tau-81 (pTau181), neurofilament light polypeptide (NFL), and the inflammatory biomarker leucine-rich-alpha-2-glycoprotein-1 (LRG1), have the most 
favorable evidence in predicting shunt responsiveness. ${ }^{5}$ Another comprehensive review by Manniche and colleagues, concluded that tTau and pTau181 might differentiate iNPH from AD, while $\mathrm{A} \beta_{1-40}$ might distinguish iNPH from healthy controls. ${ }^{10}$ Importantly, this study suggested that a combination of these biomarkers could improve diagnostic accuracy for iNPH. All the studies on which the meta-analyses by Pfanner and Manniche were based share several limitations, including small cohorts, measurement of only a subset of biomarkers and minimal long-term outcome data, making generalization of findings and drawing definite conclusions difficult.

In the present study, we aimed to evaluate the discriminative and predictive role of CSF biomarkers associated with neurodegeneration ( $\mathrm{A} \beta_{1-42}$, tTau, pTau181, NFL) and inflammation (LRG1) in a large iNPH patient cohort selected for shunt surgery with long term gait outcomes.

\section{METHODS}

\section{Standard Protocol Approvals, Registrations, and Patient Consents}

Eligible patients were those referred to our clinic for a CSF tap test (TT) after exhibiting gait, cognitive, and/or urinary dysfunction. Patients provided informed consent for biospecimen banking from 2012 -2019 under a Johns Hopkins IRB approved protocol.

\section{Selection of Patients for Shunt Surgery}

Patients underwent large-volume lumbar puncture (CSF TT) according to the guidelines for the assessment of iNPH. Patients were not asked to fast before their procedure. ${ }^{11}$ The Timed Up and Go (TUG) test was administered immediately before the large volume CSF withdrawal to assess gait velocity and dynamic balance. The TUG test was re-administered within one hour after the CSF withdrawal. Responders were defined as those who showed an improvement of $30 \%$ or greater on the TUG test. A global rating of change scale $\geq 4$ was used to define improvement in those on whom a TUG could not be obtained. ${ }^{12}$

\section{Cognitive and MRI Assessments}


The Montreal Cognitive Assessment (MOCA) test was used to assess cognitive performance. All patients also underwent a structural magnetic resonance imaging (MRI) scan of the brain; the Evan's index was calculated to estimate ventricular enlargement.

\section{CSF Sample Processing Procedures}

CSF was collected in $10 \mathrm{~mL}$ polypropylene Sarstedt tubes (62.610.018). CSF was transported at room temperature until centrifugation at $2000 \mathrm{~g}$ for 15 minutes at $5^{\circ} \mathrm{C} \pm 3^{\circ} \mathrm{C}$. Samples were coded and separated into $500 \mu \mathrm{L}$ aliquots within one hour of collection. Samples were stored in lowbinding polypropylene cryovials (Sarstedt; Ref:101093-760) at $-80^{\circ} \mathrm{C}$ until being thawed once for analysis.

\section{Response to Shunt Surgery}

Patients defined as responders (as described above) were scheduled for surgery within 60 days. Patients who underwent shunt surgery were followed at periodic intervals in the clinic according to the standard of care and the TUG assessment was repeated at every visit. The gait assessments were performed by physical therapists as part of routine clinical care. Improvement following shunt surgery was defined as an improvement in TUG time by $30 \%$, the same criterion used to identify responders to CSF TT and select patients for shunt surgery. Patients who worsened after shunt surgery were also included in the 'no improvement' group.

\section{CSF Assays}

CSF $A \beta_{1-42}, A \beta_{1-40}$, tTau and pTau181 were measured using LUMIPULSE

G1200 chemiluminescent ELISA (Fujirebio, USA) directly from the cryovials without tube transfer. A CSF internal control was run on each day that samples were analyzed. The coefficients of variation were as follows: $\mathrm{A} \beta_{1-42} 3.4 \%, \mathrm{~A} \beta_{1-40} 2.7 \%$, t-Tau $8 \%$ and pTau 181 1.8\%. CSF NFL was measured with the Simoa NF-Light Kit using the SRX platform (Quanterix, USA). Intra-assay coefficients of variation were $6.1 \%$ and $2.3 \%$ and inter-assay coefficients of variation were $<10 \%$ for quality control samples with clinically relevant low and high concentrations, respectively. CSF LRG1was measured by a solid-phase sandwich ELISA, 
Human LRG1 Assay Kit 27769 (IBL America, Minneapolis, MN, USA). The plate was analyzed using a FilterMax F3 microplate reader (Molecular Devices, USA). The intra-assay coefficient of variance was $<10 \%$, but the inter-assay coefficient of variance was $30 \%$ for the internal native CSF quality control sample, due to the individual preparation of controls, results were normalized across plates.

\section{Statistical methods}

Baseline characteristics: age, sex, race, hypertension, Evan's index, transependymal flow, the MOCA and TUG test scores, were compared for patients' responses to TT and shunt surgery. Two-sample $t$-tests or non-parametric Kruskal-Wallis tests were used for continuous variables depending on whether the variable was normally distributed based on the Shapiro-Wilk test for normality. Chi-squared tests were used for sex, hypertension, and transependymal flow. Fisher's exact tests were used for race and living status. The correlations between the biomarkers were assessed by Spearman correlations and visualized as heat maps. For patients' responses to the TT and shunt surgery, simple univariate logistic regression models and multivariate logistic regression models were used to investigate relationships with biomarkers, demographics, and baseline cognitive measures. The median values and $95 \% \mathrm{CI}$ of the regression coefficients from 10,000 runs of bootstrapping are reported. Biomarker concentrations were normalized with their sample means and standard deviations. Lasso regressions were used to select predictors for the multivariate logistic regression models, with the penalty parameters selected with 10 -fold crossvalidation. Ten-fold cross-validation was used to evaluate the logistic regression models, and the means of the area under the receiver operating curve (AUC) values were calculated and plotted to compare model performance. The cvAUC R package was used to compute $95 \%$ CIs for the cross-validated AUC estimates. One thousand bootstrap samples were used to identify optimal cutoff values of biomarker concentrations (non-normalized values) at maximum Youden Index, and accuracy, sensitivity, and specificity at the optimal cutoffs. Non-supervised random forests were also constructed to summarize the mean decrease in Gini coefficient and mean decrease in 
accuracy to establish the importance of each variable in predicting treatment outcomes. A sensitivity analysis was performed to compare the baseline characteristics between the patients with and without follow-up after shunt surgery and examine whether patients were lost to followup randomly. The analyses were carried out using R Studio Version 1.3.1073 (R version 4.0.2) and Stata 16.0. P values less than or equal to 0.05 were considered statistically significant.

\section{Data Availability}

Anonymized study data pertaining to this report are available upon request from any qualified investigator for purposes of replicating the results.

\section{RESULTS}

eFigure 1 provides a graphic representation of the total number of patients referred for iNPH assessment and the reasons for inclusion and exclusion from the study. Of the 420 patients referred for iNPH assessment, 18 had secondary etiologies, including hemorrhage, radiation, or infection, and were excluded (eFigure 1). Of the 402 patients with iNPH who underwent the TT, 121 were judged to be responders and were selected for shunt surgery. In 18 of these 121 patients, post-shunt TUG could not be measured for logistical reasons, so the global rating of change scale was administered instead. ${ }^{19}$ Response to shunt placement was seen in 90 of the 121 patients. The characteristics of the participants are summarized in Table 1. Most of the patients were followed for at least 12 months following shunt surgery; the mean duration of follow-up for the responders and non-responders to shunt surgery was 19 and 23 months, respectively, which did not differ between the groups.

Patients with improvement after TT had higher Evan's index scores and lower tTau, pTau181 and $A \beta_{1-40}$ concentrations than non-responders (Table 1). Patients who underwent shunt surgery and improved were younger, had lower TUG scores and lower levels of NFL, pTau181, tTau and $A \beta_{1-40}$ (Table 1). Strong positive correlations were found between pTau181 and tTau, $A \beta_{1-40}$ and $A \beta_{1-42}$ and $p T a u 181$ and $A \beta_{1-40}(0.77,0.77$, and 0.73 respectively, eFigure2). The distribution of these biomarkers across different groups is displayed in eFigure3. 
The univariate logistic regression models indicated that Evan's index scores,

transependymal flow, pTau181, tTau and $A \beta_{1-40}$ were associated with improvement after TT. In the multivariate logistic regression model with all four predictors, Evan's index and transependymal flow were significantly associated with improvement (odds ratio $[\mathrm{OR}]=1.09$, 95\% CI 1.04, 1.16, $\mathrm{p}<0.001 ; \mathrm{OR}=1.70,95 \%$ CI 1.07, 2.73, $\mathrm{p}=0.029$ ) (Table 2). However, the multivariate model AUC was $0.64(95 \%$ CI: $0.58,0.70)$ and that for Evan's index was $0.61(95 \%$ CI: 0.56, 0.67) (Figure 1).

For models of improvement after shunt surgery, age, NFL, pTau181, tTau, normalized LRG1, and $A \beta_{1-40}$ showed significant associations with improvement in the univariate models. In the multivariate logistic regression model, improvement after shunt surgery was significantly associated only with pTau181 (OR: 0.32, 95\% CI: 0.11, 0.63, p=0.003) (Table 3). The multivariate model had the highest AUC (0.76, 95\% CI: 0.66, 0.86) (Figure 2).

The variable importance plots showed the performance in classifying the subjects with respect to their outcomes from the non-supervised random forest algorithm based on the two types of measurements of performances in prediction, the Mean Decrease Accuracy, and the Mean Decrease Gini. The more the accuracy of the random forest decreases due to the exclusion (or permutation) of a single variable, the more important that variable is deemed, and therefore variables with a large mean decrease in accuracy are more important for classification of the outcome. The Gini coefficient is a measure of homogeneity at each split of the subjects from 0 (homogeneous) to 1 (heterogeneous). When building a decision tree, the variable with the lowest Gini coefficient is preferred as the root node. Variables that result in splits with higher homogeneity among the resulting subgroups have a higher decrease in Gini coefficient. A higher mean decrease in Gini coefficient suggests higher variable importance. The non-supervised random forest algorithm showed consistent results with the logistic regression models (Figure 3). For improvement after the TT procedure, tTau, pTau181, Evan's index, $A \beta_{1-40}$ and $A \beta_{1-42}$ showed 
the best predictive accuracy. For improvement after shunt surgery, NFL and pTau181 showed superior performance in classifying the outcome (Figure 4).

The sensitivity analysis indicated that aside for higher Evan's index, the 18 patients who did not have TUG measures, had similar age and CSF biomarker profiles to the 103 who had TUG measures, suggesting these 18 patients were not significantly different than the full cohort who underwent shunt surgery (eTable 1). Additional analysis including all 121 subjects showed that in addition to ptau181, predictors that change in statistical significance include the unadjusted LRG Normalized model (changes from being borderline significant $p=0.066$ to significant $\mathrm{p}=0.039$ ) and NFL in the adjusted model (changes from $\mathrm{p}=0.091$ to $\mathrm{p}=0.026$ ) (eTable2).

The CSF biomarkers individually did not offer much value for predicting improvement after TT as the accuracy of the predictions were not high (Table 4). However, there was stronger evidence of the predictive values of the CSF biomarkers in predicting shunt responders vs. nonresponders. We observed higher sensitivity of some of the biomarker tests such as with NFL and pTau181 (0.78, 95\% CI: $0.52,0.92$ and $0.70,95 \%$ CI: 0.48, 0.96, respectively), though these tests were not as specific individually $(0.58,95 \%$ CI: $0.25,0.88$ and $0.62,95 \%$ CI: $0.20,0.91$, respectively). This means while we would be able to correctly identify a large proportion of patients who would respond positively to shunt surgery, we would also wrongly identify some patients who would be true non-responders as responders if the biomarkers are assessed in isolation. In terms of sensitivity, tTau and $A \beta_{1-40}$ were also promising, with comparable sensitivities to NFL and pTau181, but showed weaker performance in terms of specificity.

Cutoffs for NFL $(1978.61 \pm 655.70 \mathrm{pg} / \mathrm{mL})$ and ptau181 $(36.87 \pm 12.01 \mathrm{pg} / \mathrm{mL})$ were established from an independent cohort of 50 cognitively normal individuals followed at Johns Hopkins. We found that $63(84 \%)$ patients who improved after shunt surgery had normal ptau181 and NFL values, as did 87 (71.9\%) patients who improved after TT (Table 1).

\section{DISCUSSION}


Due to comorbidities and overlapping characteristics between iNPH and other neurodegenerative illnesses, identification of relevant CSF biomarkers could improve diagnosis and treatment outcomes. ${ }^{5}$ This large cohort study with follow-up gait assessments, over approximately 20 months, shows that a combination of CSF biomarkers involved in neurodegeneration has the potential to identify the subset of iNPH subjects who are likely to have a sustained response from shunt surgery.

Clinically, iNPH is characterized by the triad of gait impairment, cognitive disturbances, and urinary incontinence. ${ }^{13}$ On imaging, enlargement of the ventricles with relatively little atrophy may be seen. ${ }^{10}$ Surgical insertion of a shunt as a method of permanent cerebrospinal fluid (CSF) diversion is currently the standard method of treatment. ${ }^{5}$ Several retrospective studies and smaller prospective studies have demonstrated that shunt treatment can alleviate symptoms in $80 \%$ of iNPH patients if it is distinguished adequately from other neurodegenerative conditions. ${ }^{6,14} \mathrm{~A}$ formal assessment of the efficacy of shunt treatment in a double-blind, randomized trial has yet to be performed, due to ethical concerns and the prior lack of valves to turn off a shunt. ${ }^{15}$ While two small scale randomized clinical trials, involving 93 and 14 patients each have been conducted about efficacy of shunt surgery in iNPH, a definitive large double-blind randomized trial is still lacking to necessitate a change in current practice guidelines. ${ }^{16,17}$

Evan's index is used in most studies of iNPH as one of the prerequisites for making a diagnosis. ${ }^{18}$ However, Evan's index alone is insufficient to select surgical candidates as it cannot differentiate iNPH from other forms of neurological diseases. ${ }^{19}$ Our study showed that Evan's index was significant in predicting immediate improvement from TT but lacked significance in predicting long-term outcomes from shunt surgery.

Our study demonstrated that $A \beta_{1-42}$ levels were not significant in determining long-term responsiveness, but, surprisingly, $A \beta_{1-40}$ was found to be a significant predictor for treatment outcomes. A $\beta_{1-40}$ levels were lower in those who improved after TT than in those who did not, 
and were associated with long-term gait improvement after shunt surgery (Table 1). This finding supports the dilution effect for $A \beta_{1-40}{ }^{20}$ The inability of $A \beta_{1-42}$ levels to predict immediate or long-term improvement may reflect the unique older population cohort seen at our center among whom amyloid pathology is more prevalent, resulting in a low $\mathrm{A} \beta_{1-42}$, even in the iNPH group. $\mathrm{A}$ recent study was also not able to validate the usefulness of $A \beta_{1-42}$ to differentiate iNPH from $\mathrm{AD}^{21}$

Using conservative improvement criteria, our study extends these findings in a large cohort by showing that elevated baseline levels of pTau181 were associated with poor long-term improvement after shunt surgery. Conversely, pTau 181 only modestly predicted immediate improvement after TT. Thus, while pTau181 may not be a good discriminatory marker, it could play an important role as a prognostic marker when combined with other CSF biomarkers. NFL, a major structural protein of myelinated axons, is an established marker of neuroaxonal integrity. ${ }^{22}$

Additionally, in our study, NFL showed significance in the univariate regression for determining shunt responsiveness but not in the multivariate analysis. Elevated NFL levels in CSF at baseline indicated poor shunt responsiveness, suggesting these patients likely suffered from comorbidities or that their iNPH was sufficiently advanced to cause neuroaxonal injury that shunting could not reverse. Irrespective of the mechanism, an elevated CSF NFL concentration is a poor prognostic marker in iNPH.

In contrast to previous reports, in our study baseline LRG1 did not discriminate between those who and did not responded to a TT. However, elevated baseline levels of LRG1 in CSF were associated with poor outcomes following shunt surgery. This finding again suggests that patients had either comorbid neurodegenerative disorders or advanced injury from iNPH.

In our current study, NFL was the best single predictor for patient response after shunt surgery, with pTau181 also having significant predictive ability. Nevertheless, the most significant predictive potential lay in combining multiple biomarkers. When NFL, pTau181 and 
normalized LRG1 were combined with age and Evan's index in a multivariate model, the predictive value improved. $A \beta_{1-40}$ and tTau, though useful individually in prediction, were not selected into the multivariate model, likely because pTau181 is highly correlated with both and they do not impart additional information. In predicting immediate improvement from TT, the combined model of pTau181, A $\beta_{1-40}$, LRG and Evan's index and transependymal flow were most predictive. Unlike in a recent study, ${ }^{21}$ we were able to show differences in biomarkers between patients with probable iNPH (those who improved after TT) compared with those who did not improve, likely reflecting the larger sample size and the stricter improvement criterion.

Many studies examining CSF biomarker in iNPH have explored the role of CSF biomarkers for $\mathrm{AD}$, in particular $\mathrm{A} \beta_{1-40}, \mathrm{~A} \beta_{1-42}$, tTau and $\mathrm{pTau} 181 . \mathrm{A} \beta \mathrm{s}$ are physiologic peptides present in the normal brain and are thought to be cleared from the brain's interstitial space via the CSF and across the blood-brain barrier. ${ }^{23}$ Any alteration in this process might cause A $\beta$ deposition. ${ }^{24}$ Since iNPH causes a reduction in CSF outflow absorption, ${ }^{25} \mathrm{~A} \beta$ deposition and subsequent neurodegeneration may also occur. ${ }^{24}$ Since $A \beta_{1-40}$ and $A \beta_{1-42}$ are part of the core CSF biomarkers for neurodegeneration, these peptides have been extensively reported in iNPH biomarker studies. ${ }^{5,26}$

Although these two kinds of $A \beta$ isoforms differ only in two amino acid residues, they vary significantly in their metabolism, physiological functions, toxicities, and aggregation mechanisms. ${ }^{27}$ In a review by Pfanner and colleagues, $A \beta_{1-42}$ showed prognostic value for iNPH, whereas $A \beta_{1-40}$ was not found to be a significant predictor. ${ }^{5}$ As posited by Graff-Radford and colleagues, use of CSF AD biomarkers can be misleading in the investigation of iNPH, potentially due to either decreased movement of these molecules from the interstitial compartment or dilution effects, where the excess CSF in iNPH dilutes physiologic CSF components. $^{28}$

Tau, a protein that stabilizes microtubules and is abundant in the neurons, is a known marker of neuronal injury. ${ }^{29-31}$ High levels of tTau are found in patients with several 
neurodegenerative diseases. ${ }^{5,32,33}$ Previous studies have not supported tTau or pTau181 as reliable predictors of long-term shunt responsiveness in patients with iNPH when used individually. ${ }^{5}$ However, Akiba and colleagues, studied a small cohort of 35 patients and found that low pTau181 levels predicted favorable long-term (three-year) prognosis after receiving a shunt, three years after surgery. ${ }^{34}$ However, there were no objective gait measures performed in the study, to quantify the improvement in this critical feature of iNPH. Another recent study looked at a composite of several AD markers in $50 \mathrm{iNPH}$ shunt recipients, and reported that both tTau and pTau181 could predict patients' outcomes after shunt surgery. ${ }^{35}$ Nevertheless, their criteria for improvement in any gait parameter were low, at 5\% in any gait measure and 1 point on the Mini Mental Status Examination.

Elevation of NFL in the brain is proportional to the degree of axonal damage in many neurological disorders, including inflammatory, neurodegenerative, traumatic and cerebrovascular diseases. ${ }^{36}$ Levels are lowest in controls, with intermediary levels in people with mild cognitive impairment, higher levels in those with $\mathrm{AD}$, and the highest levels are seen in frontotemporal dementia, amyotrophic lateral sclerosis and atypical parkinsonian disorders. ${ }^{26,32}$ The presence of NFL in CSF is associated with a 3.1-fold increased risk of mild cognitive impairment. ${ }^{37}$ Measuring CSF NFL greatly improves the distinction between many forms of neurodegenerative disease from each other and control participants. ${ }^{32}$ Accordingly, several studies have shown that iNPH patients exhibit higher CSF NFL levels than controls. ${ }^{9,38-40}$ These findings could indicate that NFL is a marker for iNPH, but the issue of comorbid neurodegenerative disorders presenting with a pre-degenerative iNPH phenotype is an alternate hypothesis. ${ }^{41}$ In previous studies, it was unclear how NFL concentration correlated with the degree of shunt surgery responsiveness.

LRG1, a novel biomarker for inflammatory diseases, ${ }^{42}$ is an astrocytic protein displaying perivascular expression in brain that increases with age and non-specific inflammatory changes. ${ }^{43,44}$ Preliminary work examining LRG1 levels in CSF has shown promising results for 
differentiating neuroinflammatory diseases with high sensitivity and specificity. ${ }^{50}$ A study by Jingami and colleagues, showed no clear evidence that LRG1 was a prospective biomarker for distinguishing between non-inflammatory neurological disorders, as there was no difference in levels between patients with iNPH and AD or responders and non-responders. ${ }^{45}$ Increased concentrations of LRG1 in CSF have been shown in patients with iNPH compared to controls, suggesting a potential role as a disease biomarker or predictor of a positive outcome after shunt placement. ${ }^{44}$ Together with NFL, LRG1 potentially allows tracking of the integrity of subcortical structures, offering some discriminatory properties in comparative analyses between iNPH and other neurodegenerative conditions. ${ }^{46}$

\section{Limitations}

This was a single-center study at a tertiary referral center, which limits generalization. A multicenter trial would be necessary for external validation. ${ }^{47}$ Since a convenience sampling method was used, there was no set schedule for testing after shunt surgery, although testing around the TT was done within one hour before and after. Furthermore, we used outcome data only from the TUG test to measure speed and dynamic balance. The cutoff of $>30 \%$ improvement in TUG as a criterion for selection of patients for shunt surgery is arbitrary and does not fully capture the spectrum of improvement after CSF drainage. We did not examine the change in cognitive measures, static balance, or endurance measures, as those are not obtained as the standard of care in our clinic and are performed only if clinical concerns arise. A recent analysis in our cohort demonstrated strong correlations between TUG and measures of balance and endurance. ${ }^{48}$ Examining all these measures would potentially improve prediction of shunt outcomes. We also did not assess APOE genotype, which can affect clinical outcome from neurological injuries. ${ }^{49}$ The patients without objective TUG measures at follow-up had slightly higher Evan's Index scores, which might be the reason why this marker was not significant for improvement after shunt surgery in the multivariate regression model for improvement assessment after shunt surgery. Nonetheless, the sensitivity analysis suggests that CSF biomarker 
profiles were not different between patients with and without TUG data. We did not have volumetric data from MRI to normalize CSF biomarker values for the increased volume of distribution of CSF in patients with ventriculomegaly to account for dilution effects. Lastly, we did not further characterize the 28 shunt non-responders clinically to ascertain their underlying neurological diagnoses eg: Parkinson Plus syndromes, Alzheimer's disease etc.

The strengths of our study include the large cohort size, long duration of follow-up, a strong improvement threshold and the use of biomarkers that reflect multiple pathologies common in aging. The study included both sensitive (NFL) and specific (pTau181) biomarkers of neurodegenerative disorders that often confound the diagnosis and selection of iNPH patients for shunt surgery.

\section{Conclusions}

In the population-based Mayo Clinic Study of Aging, among 1494 persons older than 70 years, $20 \%$ had ventriculomegaly (Evans index of 0.3 or greater) and $5 \%$ had ventriculomegaly and either a tight high convexity (occluded sulci at the high convexity) or extra ventricular hydrocephalus (cerebrospinal fluid collection outside the ventricles not due to atrophy) suggestive of NPH. ${ }^{50}$ In a large population-based study from Sweden, the prevalence of iNPH was estimated at $0.2 \%$ between $70-79$ years, and $5.9 \%$ for those 80 years and older. ${ }^{8}$ Therefore, there is potentially a large population that could benefit from shunt surgery if patients with potential good long-term outcomes can be identified before shunt surgery.

The role of CSF biomarkers for iNPH that would allow clinicians to distinguish it from other neurodegenerative disorders has been assessed in multiple studies. In contrast, the role of CSF biomarkers in predicting long-term outcomes are less well studied but are of increasing interest. Our study extends the current literature by evaluating not just individual biomarkers but also composites of the most studied CSF biomarkers to predict long-term outcomes after shunt surgery. At the same time, their role in predicting immediate improvement from a TT is limited. Mechanistically, these findings would support the contention, in a subset of iNPH patient with 
elevated biomarkers who improve after a TT, there are comorbid neurodegenerative disorders

like AD, atypical Parkinsonian syndromes and vascular dementia, or there exists irreversible axonal injury from iNPH. These preliminary findings will need to be replicated in other cohorts and, more importantly, looked at in a prospective clinical trial before changes to current clinical practice can be recommended. 


\begin{tabular}{|c|c|c|}
\hline Name & Location & Contribution \\
\hline $\begin{array}{l}\text { Jacqueline Darrow, } \\
\text { MS }\end{array}$ & $\begin{array}{l}\text { Johns Hopkins University } \\
\text { School of Medicine }\end{array}$ & $\begin{array}{l}\text { Study concept or design, interpretation } \\
\text { of the data, drafted and revised the } \\
\text { manuscript for content, study } \\
\text { supervision and coordination }\end{array}$ \\
\hline $\begin{array}{l}\text { Alexandria Lewis, } \\
\text { BS }\end{array}$ & $\begin{array}{l}\text { Johns Hopkins University } \\
\text { School of Medicine }\end{array}$ & $\begin{array}{l}\text { Study concept or design, interpretation } \\
\text { of the data, drafted and revised the } \\
\text { manuscript for content, study } \\
\text { supervision and coordination }\end{array}$ \\
\hline $\begin{array}{l}\text { Seema Gulyani, } \\
\text { PhD }\end{array}$ & $\begin{array}{l}\text { Johns Hopkins University } \\
\text { School of Medicine }\end{array}$ & Study supervision and coordination \\
\hline $\begin{array}{l}\text { Kristina } \\
\text { Khingelova, } \\
\text { PA-C }\end{array}$ & $\begin{array}{l}\text { Johns Hopkins University } \\
\text { School of Medicine }\end{array}$ & Study supervision and coordination \\
\hline $\begin{array}{l}\text { Aruna Rao, } \\
\text { MD }\end{array}$ & $\begin{array}{l}\text { Johns Hopkins University } \\
\text { School of Medicine }\end{array}$ & Study supervision and coordination \\
\hline $\begin{array}{l}\text { Jiangxia Wang, } \\
\text { MS }\end{array}$ & $\begin{array}{l}\text { Johns Hopkins University } \\
\text { Bloomberg School of } \\
\text { Public Health }\end{array}$ & $\begin{array}{l}\text { Performed the statistical analyses, } \\
\text { interpretation of the data, revised the } \\
\text { manuscript for content }\end{array}$ \\
\hline $\begin{array}{l}\text { Yifan Zhang, } \\
\text { MS }\end{array}$ & $\begin{array}{l}\text { Johns Hopkins University } \\
\text { Bloomberg School of } \\
\text { Public Health }\end{array}$ & $\begin{array}{l}\text { Performed the statistical analyses, } \\
\text { interpretation of the data, revised the } \\
\text { manuscript for content }\end{array}$ \\
\hline $\begin{array}{l}\text { Mark Luciano, } \\
\text { MD }\end{array}$ & $\begin{array}{l}\text { Johns Hopkins University } \\
\text { School of Medicine }\end{array}$ & Study supervision and coordination \\
\hline $\begin{array}{l}\text { Sevil Yasar, } \\
\text { MD }\end{array}$ & $\begin{array}{l}\text { Johns Hopkins University } \\
\text { School of Medicine }\end{array}$ & Study supervision and coordination \\
\hline $\begin{array}{l}\text { Abhay Moghekar } \\
\text { MB,BS }\end{array}$ & $\begin{array}{l}\text { Johns Hopkins University } \\
\text { School of Medicine }\end{array}$ & $\begin{array}{l}\text { Supervised the analysis of } \\
\text { CSF, study concept or design, } \\
\text { interpretation of the data, drafted and } \\
\text { revised the manuscript for content, } \\
\text { study supervision and coordination }\end{array}$ \\
\hline
\end{tabular}


Supplement-http://links.lww.com/CPJ/A327

\section{References}

1. Hakim S, Adams RD. The Special Clinical Problem of Symptomatic Hydrocephalus with Normal Cerebrospinal Fluid Pressure Observations on Cerebrospinal Fluid Hydrodynamics.

2. Kiefer M, Unterberg A. Differenzialdiagnose und therapie des normaldruckhydrozephalus. Dtsch Arztebl Int. Deutscher Arzte-Verlag GmbH; 2012;109:15-26.

3. Hebb AO, Cusimano MD. TOPIC REVIEW Idiopathic Normal Pressure Hydrocephalus: A Systematic Review of Diagnosis and Outcome [online]. Accessed at: https://academic.oup.com/neurosurgery/article/49/5/1166/2751908.

4. Halperin JJ, Kurlan R, Schwalb JM, Cusimano MD, Gronseth G, Gloss D. Practice guideline: Idiopathic normal pressure hydrocephalus: Response to shunting and predictors of response. Neurology. 2015;85:2063-2071.

5. Pfanner T, Henri-Bhargava A, Borchert S. Cerebrospinal Fluid Biomarkers as Predictors of Shunt Response in Idiopathic Normal Pressure Hydrocephalus: A Systematic Review. Can J Neurol Sci. Cambridge University Press; 2018;45:3-10.

6. Feletti A, D’Avella D, Wikkels $\emptyset$ C, et al. Ventriculoperitoneal Shunt Complications in the European Idiopathic Normal Pressure Hydrocephalus Multicenter Study. Oper Neurosurg. Oxford University Press; 2019;17:97-101.

7. Jeppsson A, Wikkelsö C, Blennow K, et al. CSF biomarkers distinguish idiopathic normal pressure hydrocephalus from its mimics. J Neurol Neurosurg Psychiatry. Epub 2019.:1-7.

8. Jaraj D, Rabiei K, Marlow T, Jensen C, Skoog I, Wikkelsø C. Prevalence of idiopathic normal-pressure hydrocephalus. 2014.

9. Tullberg M, Blennow K, Månsson JE, Fredman P, Tisell M, Wikkelsö C. Cerebrospinal 
fluid markers before and after shunting in patients with secondary and idiopathic normal pressure hydrocephalus. Cerebrospinal Fluid Res. 2008;5.

10. Manniche C, Hejl AM, Hasselbalch SG, Simonsen AH. Cerebrospinal Fluid Biomarkers in Idiopathic Normal Pressure Hydrocephalus versus Alzheimer's Disease and Subcortical Ischemic Vascular Disease: A Systematic Review. J. Alzheimer’s Dis. IOS Press; 2019. p. 267-279.

11. Darrow JA, Calabro A, Gannon S, et al. Effect of Patient-Specific Preanalytic Variables on CSF A $11-42$ Concentrations Measured on an Automated Chemiluminescent Platform. J Appl Lab Med [online serial]. Epub 2020 Nov 29. Accessed at: https://academic.oup.com/jalm/advance-article/doi/10.1093/jalm/jfaa145/6010325.

12. Gallagher R, Marquez J, Osmotherly P. Clinimetric Properties and Minimal Clinically Important Differences for a Battery of Gait, Balance, and Cognitive Examinations for the Tap Test in Idiopathic Normal Pressure Hydrocephalus. Clin Neurosurg. Oxford University Press; 2019;84:E378-E384.

13. Nassar BR, Lippa CF. Idiopathic Normal Pressure Hydrocephalus. Gerontol Geriatr Med [online serial]. 2016;2:233372141664370, Accessed at: http://journals.sagepub.com/doi/10.1177/2333721416643702.

14. Ghosh S, Lippa C. Diagnosis and prognosis in idiopathic normal pressure hydrocephalus. Am J Alzheimers Dis Other Demen. SAGE Publications Inc.; 2014;29:583-589.

15. McGirr A, Mohammed S, Kurlan R, Cusimano MD. Clinical equipoise in idiopathic normal pressure hydrocephalus: A survey of physicians on the need for randomized controlled trials assessing the efficacy of cerebrospinal fluid diversion. J Neurol Sci. 2013;333:13-18.

16. Tisell M, Tullberg M, Hellström P, Edsbagge M, Högfeldt M, Wikkelsö C. Shunt surgery in patients with hydrocephalus and white matter changes: Clinical article. J Neurosurg. 2011;114:1432-1438. 
17. Kazui H, Miyajima M, Mori E, et al. Lumboperitoneal shunt surgery for idiopathic normal pressure hydrocephalus (SINPHONI-2): An open-label randomised trial. Lancet Neurol. Lancet Publishing Group; 2015;14:585-594.

18. Tarnaris A, Kitchen ND, Watkins LD. Noninvasive biomarkers in normal pressure hydrocephalus: Evidence for the role of neuroimaging - A review. J. Neurosurg. 2009. p. 837-851.

19. Tarnaris A, Toma AK, Chapman MD, Keir G, Kitchen ND, Watkins LD. Use of cerebrospinal fluid amyloid- $\beta$ and total tau protein to predict favorable surgical outcomes in patients with idiopathic normal pressure hydrocephalus: Clinical article. J Neurosurg. 2011;115:145-150.

20. Santangelo R, Cecchetti G, Bernasconi MP, et al. Cerebrospinal fluid amyloid- $\beta$ 42, total tau and phosphorylated tau are low in patients with normal pressure hydrocephalus: Analogies and differences with Alzheimer's disease. J Alzheimer's Dis. IOS Press; 2017;60:183-200.

21. Taghdiri F, Gumus M, Algarni M, Fasano A, Tang-Wai D, Tartaglia MC. Association Between Cerebrospinal Fluid Biomarkers and Age-related Brain Changes in Patients with Normal Pressure Hydrocephalus. Sci Rep. Nature Research; 2020;10.

22. Magdalinou NK, Paterson RW, Schott JM, et al. A panel of nine cerebrospinal fluid biomarkers may identify patients with atypical parkinsonian syndromes. J Neurol Neurosurg Psychiatry. BMJ Publishing Group; 2015;86:1240-1247.

23. Motter R, Vigo-Pelfrey C, Kholodenko D, et al. Peptide*, in the Reduction of P-Amyloid Cerebrospinal Fluid of Patients with Alzheimer's Disease. 1995.

24. Ray B, Reyes PF, Lahiri DK. Biochemical studies in Normal Pressure Hydrocephalus (NPH) patients: Change in CSF levels of amyloid precursor protein (APP), amyloid-beta (A $\beta$ ) peptide and phospho-tau. J Psychiatr Res. 2011;45:539-547.

25. Hamlat A, Adn M, Sid-ahmed S, Askar B, Pasqualini E. Theoretical considerations on the Copyright @ 2022 The Author(s). Published by Wolters Kluwer Health, Inc. on behalf of the American Academy of Neurology. 
pathophysiology of normal pressure hydrocephalus (NPH) and NPH-related dementia.

Med Hypotheses. 2006;67:115-123.

26. Zetterberg H, Skillbäck T, Mattsson N, et al. Association of cerebrospinal fluid neurofilament light concentration with Alzheimer disease progression. JAMA Neurol. American Medical Association; 2016;73:60-67.

27. Qiu T, Liu Q, Chen YX, Zhao YF, Li YM. A $\beta 42$ and A $\beta 40$ : similarities and differences. J Pept Sci. John Wiley and Sons Ltd; 2015;21:522-529.

28. Graff-Radford NR. Alzheimer CSF biomarkers may be misleading in normal-pressure hydrocephalus. Neurology. 2014;83:1573-1575.

29. Johnson GVW, Seubert P, Cox TM, Motter R, Brown P. The -Protein in Human Cerebrospinal Fluid in Alzheimer' s Disease Consists of Proteolytically Derived Fragments. J. Neurochem 1997.

30. Kapaki EN, Paraskevas GP, Tzerakis NG, et al. Cerebrospinal fluid tau, phospho-tau181 and $\beta$-amyloid 1-42 in idiopathic normal pressure hydrocephalus: A discrimination from Alzheimer's disease. Eur J Neurol. 2007;14:168-173.

31. Zetterberg H, Smith DH, Blennow K. Biomarkers of mild traumatic brain injury in cerebrospinal fluid and blood. Nat Rev Neurol. 2013;9:201-210.

32. Olsson B, Portelius E, Cullen NC, et al. Association of Cerebrospinal Fluid Neurofilament Light Protein Levels with Cognition in Patients with Dementia, Motor Neuron Disease, and Movement Disorders. JAMA Neurol. 2019;76.

33. Van Harten AC, Kester MI, Visser PJ, et al. Tau and p-tau as CSF biomarkers in dementia: A meta-analysis. Clin Chem Lab Med. 2011;49:353-366.

34. Akiba C, Nakajima M, Miyajima M, et al. Change of Amyloid- $\beta$ 1-42 Toxic Conformer Ratio after Cerebrospinal Fluid Diversion Predicts Long-Term Cognitive Outcome in Patients with Idiopathic Normal Pressure Hydrocephalus. J Alzheimer's Dis. IOS Press; 2018;63:989-1002. 
35. Migliorati K, Panciani PP, Pertichetti M, et al. P-Tau as prognostic marker in long term follow up for patients with shunted iNPH. Neurol Res [online serial]. Taylor \& Francis; 2020;00:1-8. Accessed at: https://doi.org/10.1080/01616412.2020.1831300.

36. Gaetani L, Höglund K, Parnetti L, et al. A new enzyme-linked immunosorbent assay for neurofilament light in cerebrospinal fluid: Analytical validation and clinical evaluation. Alzheimer's Res Ther. BioMed Central Ltd.; 2018;10.

37. Kern S, Syrjanen JA, Blennow K, et al. Association of Cerebrospinal Fluid Neurofilament Light Protein with Risk of Mild Cognitive Impairment among Individuals Without Cognitive Impairment. JAMA Neurol. American Medical Association; 2019;76:187-193.

38. Tullberg M, Rosengren L, Blomsterwall E, Karlsson J, Wikkelso C. CSF neurofilament and glial fibrillary acidic protein in normal pressure hydrocephalus. Epub 1998.

39. Tullberg M, Blennow K, Månsson JE, Fredman P, Tisell M, Wikkelsö C. Ventricular cerebrospinal fluid neurofilament protein levels decrease in parallel with white matter pathology after shunt surgery in normal pressure hydrocephalus. Eur J Neurol. $2007 ; 14: 248-254$.

40. Jeppsson A, Höltta M, Zetterberg H, Blennow K, Wikkelsø C, Tullberg M. Amyloid mismetabolism in idiopathic normal pressure hydrocephalus. Fluids Barriers CNS. BioMed Central Ltd.; 2016;13.

41. Espay AJ, Da Prat GA, Dwivedi AK, et al. Deconstructing normal pressure hydrocephalus: Ventriculomegaly as early sign of neurodegeneration. Ann Neurol. 2017;82:503-513.

42. Chong PF, Sakai Y, Torisu H, et al. Leucine-rich alpha-2 glycoprotein in the cerebrospinal fluid is a potential inflammatory biomarker for meningitis. J Neurol Sci. Elsevier B.V.; 2018;392:51-55.

43. Nakajima M, Miyajima M, Ogino I, et al. Leucine-rich $\alpha$-2-glycoprotein is a marker for idiopathic normal pressure hydrocephalus. Acta Neurochir (Wien). 2011;153:1339-1346. 
44. Miyajima M, Nakajima M, Motoi Y, et al. Leucine-Rich $\alpha 2-$ Glycoprotein Is a Novel Biomarker of Neurodegenerative Disease in Human Cerebrospinal Fluid and Causes Neurodegeneration in Mouse Cerebral Cortex. Yan R, editor. PLoS One [online serial]. 2013;8:e74453. Accessed at: https://dx.plos.org/10.1371/journal.pone.0074453.

45. Jingami N, Asada-Utsugi M, Uemura K, et al. Idiopathic normal pressure hydrocephalus has a different cerebrospinal fluid biomarker profile from alzheimer's disease. $\mathbf{J}$ Alzheimer's Dis. IOS Press; 2015;45:109-115.

46. Schirinzi T, Sancesario GM, Di Lazzaro G, et al. Cerebrospinal fluid biomarkers profile of idiopathic normal pressure hydrocephalus. J. Neural Transm. Springer-Verlag Wien; 2018. p. 673-679.

47. Bellomo R, Warrillow SJ, Reade MC. Why we should be wary of single-center trials. Crit Care Med [online serial]. 2009;37:3114-3119. Accessed at: http://journals.lww.com/00003246-200912000-00017.

48. Davis A, Yasar S, Emerman I, et al. Standardized regression-based clinical change score cutoffs for normal pressure hydrocephalus. BMC Neurol [online serial]. 2020;20:140. Accessed at: https://bmcneurol.biomedcentral.com/articles/10.1186/s12883-020-01719-y.

49. Gudmundsson G, Kristjansdottir G, Cook E, Olafsson I. Association of ApoE genotype with clinical features and outcome in idiopathic normal pressure hydrocephalus (iNPH): A preliminary report. Acta Neurochir (Wien). 2009;151:1511-1512.

50. Graff-Radford N, Gunter J, Thomas C, Crook J, Jones D, Graf-Radford J, Boeve B, Knopman D, Petersen R JC. Ventriculomegaly is a Biomarker of Gait and Cognitive Decline. Alzheimer's Dement. 2017;13:1092. 


\section{Table 1. Patient baseline characteristics compared by responses to Tap Test (TT) and shunt surgery}

\begin{tabular}{|c|c|c|c|c|c|c|}
\hline Characteristics & & sponse $(n=402)$ & & Shunt Su & Response (n=103) & \\
\hline & $\begin{array}{r}\text { No Improvement } \\
(\mathrm{n}=281)\end{array}$ & $\begin{array}{r}\text { Improved } \\
(\mathrm{n}=121)\end{array}$ & $\mathrm{p}$-value & $\begin{array}{r}\text { No Improvement } \\
(\mathrm{n}=28)\end{array}$ & $\begin{array}{r}\text { Improved } \\
(\mathrm{n}=75)\end{array}$ & p-value \\
\hline Age, mean (SD) & $78.0(7.6)$ & $77.2(6.4)$ & 0.330 & $79.8(6.5)$ & $76.4(6.0)$ & 0.014 \\
\hline Male gender, $\mathbf{n}(\%)$ & $179(63.7 \%)$ & $80(66.1 \%)$ & 0.643 & $21(75.0)$ & $47(62.7)$ & 0.240 \\
\hline Race, $\mathbf{n}(\%)$ & & & 0.470 & & & 0.679 \\
\hline Caucasian & $261(92.9 \%)$ & $116(95.9 \%)$ & & $28(100 \%)$ & $71(94.7 \%)$ & \\
\hline African American & $15(5.3 \%)$ & $3(2.5 \%)$ & & 0 & $3(4.0 \%)$ & \\
\hline Other & $5(1.8 \%)$ & $2(1.70 \%)$ & & 0 & $1(1.3 \%)$ & \\
\hline Living Status, deceased, n (\%) & $14(5.0 \%)$ & $5(4.1 \%)$ & 0.803 & $3(10.7 \%)$ & $1(1.3 \%)$ & 0.060 \\
\hline Hypertension, n (\%) & $226(80.4 \%)$ & $100(82.6 \%)$ & 0.702 & $26(92.9 \%)$ & $59(78.7 \%)$ & 0.143 \\
\hline MoCA Score, mean (SD) & $21.2(5.9)$ & $21.1(5.6)$ & 0.844 & $19.4(7.0)$ & $21.7(5.2)$ & 0.071 \\
\hline MRI-Evan's Index (0-1), mean (SD) & $0.36(0.05)$ & $0.38(0.04)$ & 0.001 & $0.37(0.04)$ & $0.38(0.04)$ & 0.211 \\
\hline Transependymal Flow, n (\%) & $77(27.4 \%)$ & $48(39.7 \%)$ & 0.020 & $9(32.1 \%)$ & $31(41.3 \%)$ & 0.532 \\
\hline TUG Score Baseline, mean (SD) $\dagger$ & $24.5(41.4)$ & $34.7(49.7)$ & 0.036 & $35.0(54.7)$ & $36.3(53.2)$ & 0.912 \\
\hline TUG Score Post shunt, mean (SD) & & $42.2(82.2)$ & & $107.1(128.0)$ & $18.0(33.9)$ & $<0.001$ \\
\hline $\begin{array}{l}\text { Interval between baseline and last follow-up in } \\
\text { months, mean (SD) }\end{array}$ & & $19.99(18.36))$ & & $22.2(19.3)$ & $20.0(18.8)$ & 0.612 \\
\hline NFL, median (IQR) & $1741(1077,3052)$ & $1512(944,2404)$ & 0.073 & $2504(1337,4716)$ & $1298(933,1940)$ & 0.002 \\
\hline LRG Normalized, median (IQR) & $259(160,457)$ & $269(182,451)$ & 0.411 & $269(204,706)$ & $280(182,470)$ & 0.402 \\
\hline pTau181, median (IQR) & $27.3(21,41.3)$ & $23.4(17.8,34)$ & 0.002 & $33.9(25.1,62.7)$ & $20.9(17.6,31.0)$ & $<0.001$ \\
\hline tTau, median (IQR) & $250(159,386)$ & $219(137,309)$ & 0.039 & $296(163,531)$ & $211(132,293)$ & 0.011 \\
\hline$A \beta_{1-42}$, median (IQR) & $809(604,1070)$ & $757(510,1014)$ & 0.103 & $755(579,1079)$ & $746(496,1000)$ & 0.370 \\
\hline$A \beta_{1-40}$, median (IQR) & $7395(5600,9456)$ & $6560(4857,8522)$ & 0.004 & $8390(5189,10481)$ & $5988(4581,8168)$ & 0.010 \\
\hline $\mathbf{A} \beta_{1-42} / \mathbf{A} \beta_{1-40}$, median (IQR) & $0.13(0.09,0.14)$ & $0.13(0.09,0.14)$ & 0.253 & $0.10(0.08,0.14)$ & $0.13(0.10,0.14)$ & 0.074 \\
\hline tTau /amyloid ratio, median (IQR) & $1999(1223,3793)$ & $1934(1064,2921)$ & 0.086 & $3285(1588,5520)$ & $1854(994,2471)$ & 0.005 \\
\hline ptau181 /amyloid ratio, median (IQR) & $223(155,450)$ & $185(134,330)$ & 0.021 & $356(169,593)$ & $180(127,276)$ & 0.001 \\
\hline$A \beta_{1-42} /$ tTau, median (IQR) & $3.49(1.98,5.60)$ & $3.49(2.34,5.52)$ & 0.728 & $2.93(1.59,4.25)$ & $3.62(2.40,5.52)$ & 0.078 \\
\hline A $\beta_{1-42} /$ pTau181, median (IQR) & $32.0(17.4,44.3)$ & $35.7(19.3,43.6)$ & 0.398 & $23.2(12.7,38.8)$ & $35.9(20.7,44.5)$ & 0.012 \\
\hline Normal pTau181 and normal NFL, n (\%) * & $160(56.9 \%)$ & $87(71.9 \%)$ & 0.007 & $10(35.7 \%)$ & $63(84.0 \%)$ & $<0.001$ \\
\hline
\end{tabular}


TT, large volume lumbar puncture. MoCA, Montreal Cognitive Assessment. TUG, Timed Up and Go. NFL, Neurofilament Light Assay. LRG, Leucine-rich alpha-2 glycoprotein.

$\dagger$ Patients who were unable to walk were assigned a baseline TUG score of 300. Nine patients had baseline TUG score greater than 200. If the nine patients are excluded, the mean baseline TUG is 19.5 (SD: 17.8, $\mathrm{n}=271$ ) for patients without improvement after TT and 26.4 (SD: 20.3, $\mathrm{n}=117$ ) for patients with improvement.

\$ Patients who were unable to walk were assigned a post shunt TUG score of 300. If the nine patients are excluded, the mean post shunt TUG is 29.9 (SD: 36.5 , $\mathrm{n}=20$ ) for patients without improvement and 14.2 (SD: 7.6, n=74) for patients with improvement.

* Normal pTau defined as $<53.8 \mathrm{pg} / \mathrm{ml}$. Normal NFL defined as $<2417 \mathrm{pg} / \mathrm{ml}$. 
Table 2. Logistic regression models for relationships between patient responses to TT and baseline characteristics and biomarkers $(n=402)$.

\begin{tabular}{|c|c|c|c|c|c|c|}
\hline \multirow[b]{2}{*}{ Predictors } & \multicolumn{3}{|c|}{ Unadjusted Models } & \multicolumn{3}{|c|}{ Adjusted models } \\
\hline & $\begin{array}{l}\text { Odds } \\
\text { Ratio }\end{array}$ & $95 \% \mathrm{CI}$ & p-value & Odds Ratio & $95 \% \mathrm{CI}$ & p-value \\
\hline Age & 0.99 & $(0.96,1.01)$ & 0.296 & & & \\
\hline Female Gender & 1.11 & $(0.71,1.78)$ & 0.647 & & & \\
\hline $\begin{array}{l}\text { MRI Evan's Index, per } 0.01 \\
\text { pts }\end{array}$ & 1.09 & $(1.03,1.15)$ & $<0.001$ & 1.09 & $(1.04,1.16)$ & $<0.001$ \\
\hline Transependymal Flow & 1.75 & $(1.11,2.74)$ & 0.016 & 1.70 & $(1.07,2.73)$ & 0.029 \\
\hline MoCA $(<22)$ & $\begin{array}{l}1.00 \\
0.80\end{array}$ & $\begin{array}{l}(0.62,1.61) \\
(0.44,1.41)\end{array}$ & $\begin{array}{l}0.999 \\
0.435\end{array}$ & & & \\
\hline NFL & 0.97 & $(0.55,1.21)$ & 0.806 & & & \\
\hline pTau181 & 0.70 & $(0.47,0.91)$ & 0.006 & 0.75 & $(0.46,1.05)$ & 0.107 \\
\hline tTau & 0.77 & $(0.58,0.97)$ & 0.023 & & & \\
\hline LRG Normalized & 1.12 & $(0.87,1.37)$ & 0.314 & 1.14 & $(0.88,1.38)$ & 0.266 \\
\hline $\mathrm{A} \beta_{1-40}$ & 0.74 & $(0.56,0.94)$ & 0.011 & 0.92 & $(0.68,1.23)$ & 0.576 \\
\hline
\end{tabular}

The sample size for models with MRI and MoCA is 401 . The sample size for the multivariate model is 400 .

The predictors for the adjusted model were selected by LASSO regression.

Median odds ratio from bootstrap samples are reported. P-value was obtained by determining the proportions of bootstrapped coefficients smaller and larger than zero, and multiplying the minimum proportion by two. 
Table 3. Logistic regression models for relationships between improvement after shunt surgery and baseline characteristics and biomarkers $(n=103)$.

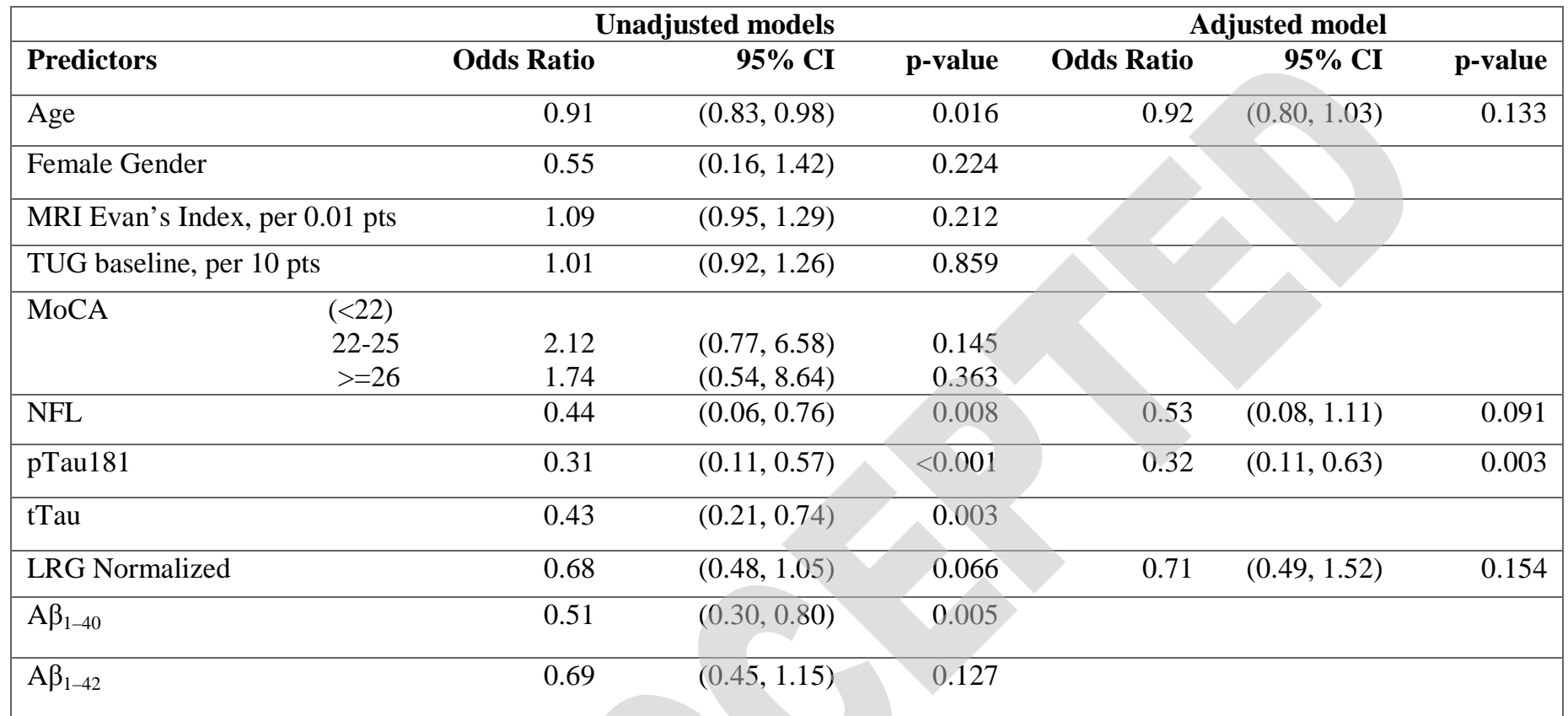

The predictors for the adjusted model were selected by LASSO regression.

Median odds ratio from bootstrap samples are reported. P-value was obtained by determining the proportions of bootstrapped coefficients smaller and larger than zero and multiplying the minimum proportion by two 
Table 4: Optimal cutoff points for biomarkers for Tap Test (TT) and shunt surgery

\begin{tabular}{|c|c|c|c|c|c|c|}
\hline & Biomarker & $\begin{array}{l}\text { Optimal Cutoff, } \\
\text { Median (95\% CI) }\end{array}$ & $\begin{array}{l}\text { Direction } \\
\text { Corresponding } \\
\text { to Improvement }\end{array}$ & $\begin{array}{l}\text { Accuracy, } \\
\text { Mean }(95 \% \text { CI })\end{array}$ & $\begin{array}{l}\text { Sensitivity, } \\
\text { Mean }(95 \% \text { CI) }\end{array}$ & $\begin{array}{l}\text { Specificity, } \\
\text { Mean }(95 \% \text { CI })\end{array}$ \\
\hline \multirow[t]{6}{*}{ Tap Test } & NFL & $1575(858,2730)$ & $<=$ & $0.53(0.40,0.68)$ & $0.49(0.13,0.79)$ & $0.55(0.27,0.89)$ \\
\hline & LRG Normalized & $170(139,1162)$ & $>=$ & $0.46(0.36,0.68)$ & $0.64(0.05,0.89)$ & $0.38(0.16,0.95)$ \\
\hline & pTau181 & $22.1(19.9,36.7)$ & $<=$ & $0.61(0.42,0.70)$ & $0.47(0.29,0.83)$ & $0.67(0.25,0.82)$ \\
\hline & tTau & $234(140,365)$ & $<=$ & $0.53(0.41,0.66)$ & $0.53(0.20,0.82)$ & $0.53(0.26,0.82)$ \\
\hline & $\mathbf{A} \boldsymbol{\beta}_{1-42}$ & $700(458,1202)$ & $<=$ & $0.57(0.36,0.68)$ & $0.41(0.13,0.85)$ & $0.64(0.16,0.88)$ \\
\hline & $\mathbf{A} \boldsymbol{\beta}_{1-40}$ & $6033(5200,8781)$ & $<=$ & $0.60(0.42,0.68)$ & $0.46(0.24,0.75)$ & $0.65(0.29,0.82)$ \\
\hline \multirow{6}{*}{ Shunt Surgery } & NFL & $1985(1424,2630)$ & $<=$ & $0.72(0.56,0.84)$ & $0.78(0.52,0.92)$ & $0.58(0.25,0.88)$ \\
\hline & LRG Normalized & $257(50, \infty)$ & $>=$ & $0.53(0.26,0.77)$ & $0.61(0,1)$ & $0.31(0,1)$ \\
\hline & pTau181 & $26.1(23.5,42.1)$ & $<=$ & $0.68(0.55,0.81)$ & $0.70(0.48,0.96)$ & $0.62(0.20,0.91)$ \\
\hline & tTau & $307(133,486)$ & $<=$ & $0.67(0.39,0.82)$ & $0.77(0.22,0.97)$ & $0.43(0.10,0.91)$ \\
\hline & $\mathbf{A} \boldsymbol{\beta}_{1-42}$ & $1460(474,1617)$ & $<=$ & $0.62(0.32,0.85)$ & $0.72(0.19,1)$ & $0.34(0,0.85)$ \\
\hline & $\mathbf{A} \boldsymbol{\beta}_{1-40}$ & $9570(6389,9967)$ & $<=$ & $0.69(0.48,0.84)$ & $0.79(0.42,0.97)$ & $0.43(0.13,0.75)$ \\
\hline
\end{tabular}

Optimal cutoff values were evaluated using 1000 bootstrap samples and identified based on maximum Youden Index. Mean estimates along with $5 \%$ and $95 \%$ percentile estimates for out-of-bag accuracy, sensitivity, and specificity are reported. 
Figure 1: The plot presents the ROC curves generated from the univariate and the multivariate regression (red) models listed in Table 2. The multivariate model uses LRG, pTau, A $\beta_{1-40}$, Evan's index and transependymal flow as predictors and has the greatest AUC of 0.64 (95\% CI: $0.58-0.70)$.

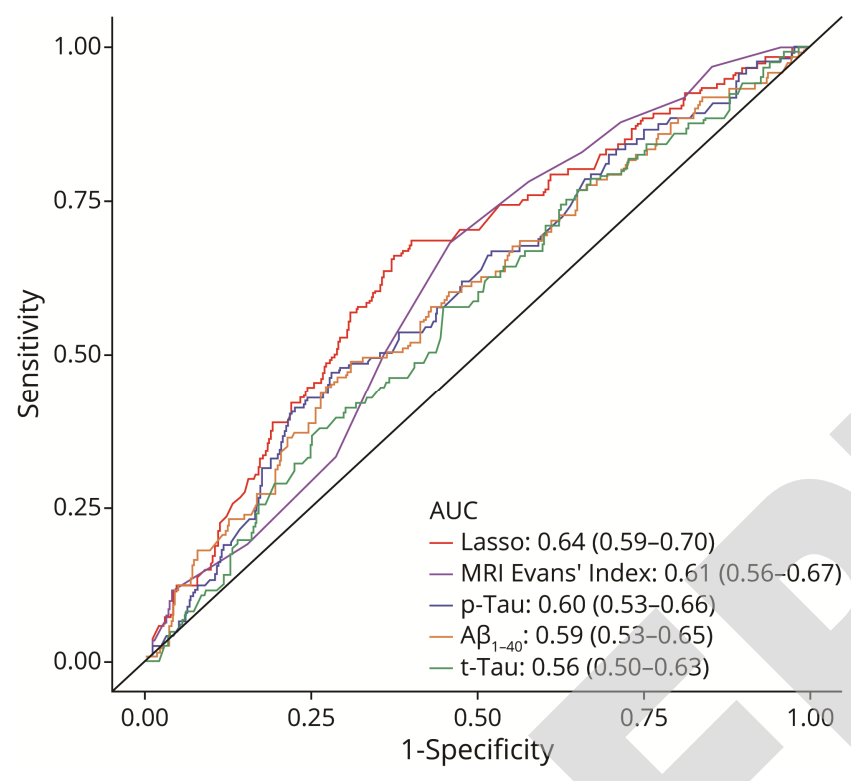


Figure 2: The plot presents the ROC curves generated from the univariate and multivariate (red) regression models listed in Table 3. The multivariate model uses age, NFL, pTau and LRG as predictors has the greatest AUC of 0.76 (95\% CI: 0.66-0.86).

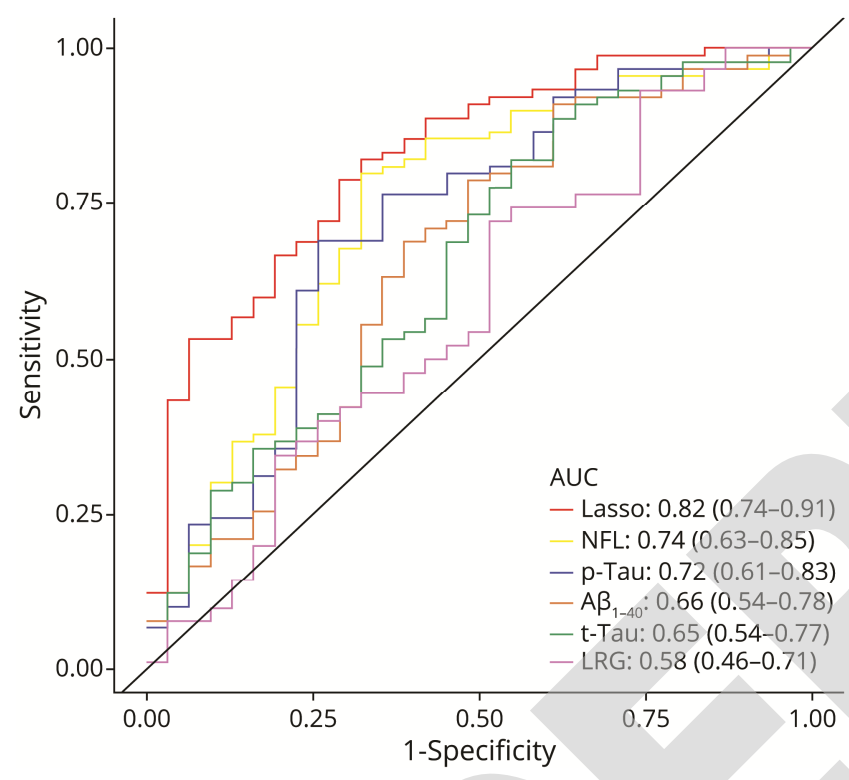




\section{Figure 3: Variable importance plot from non-supervised random forest algorithm for improvement after TT procedure.}

The mean decrease in accuracy attributed to a variable is determined during the classification error calculation phase. The more the accuracy of the random forest decreases due to the exclusion (or permutation) of a single variable, the more important that variable is deemed, and therefore variables with a large mean decrease in accuracy are more important for classification of the outcome.

The mean decrease in Gini coefficient is a measure of how each variable contributes to the homogeneity (purity) of the nodes and leaves in the resulting random forest. The Gini coefficient is a measure of homogeneity from 0 (homogeneous) to 1 (heterogeneous). The changes in Gini are summed for each variable and normalized at the end of the calculation. Variables that result in nodes with higher homogeneity have a higher decrease in Gini coefficient.

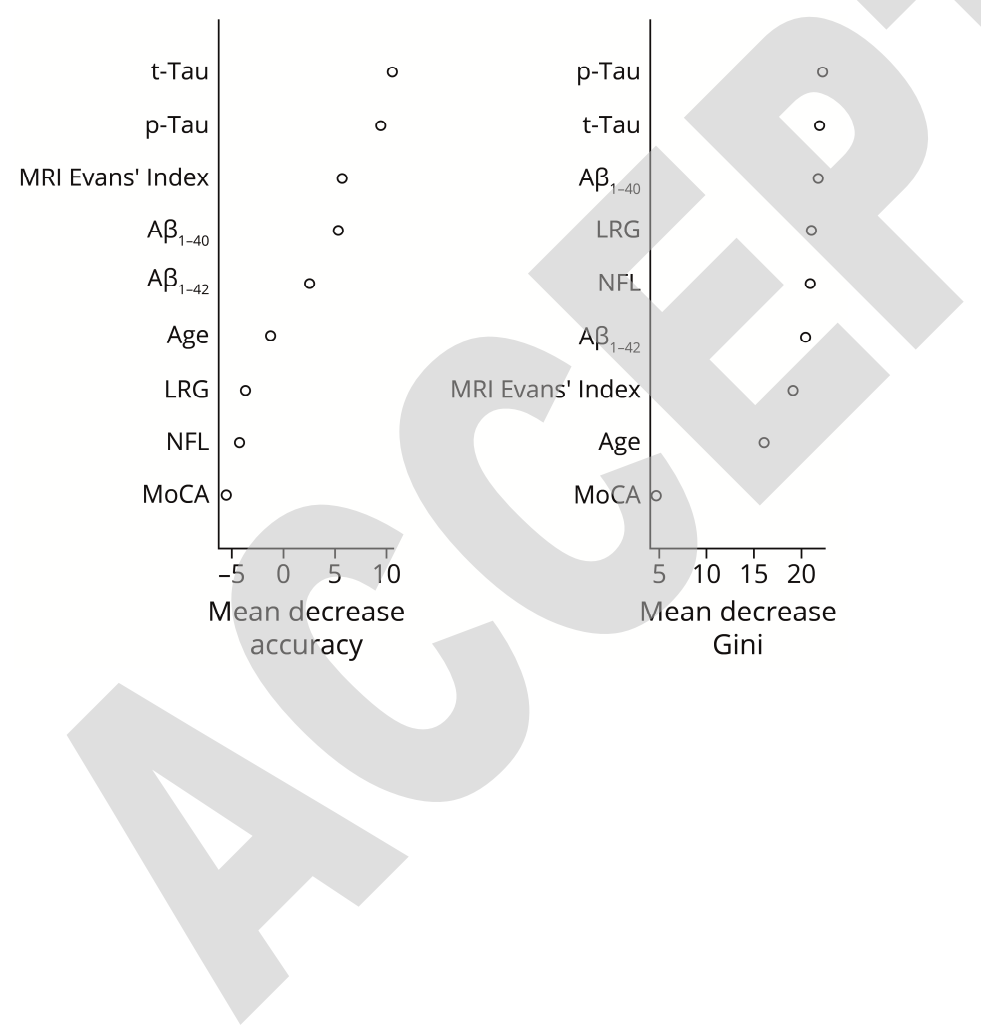


Figure 4: Variable importance plot from non-supervised random forest algorithm for improvement after shunt surgery.

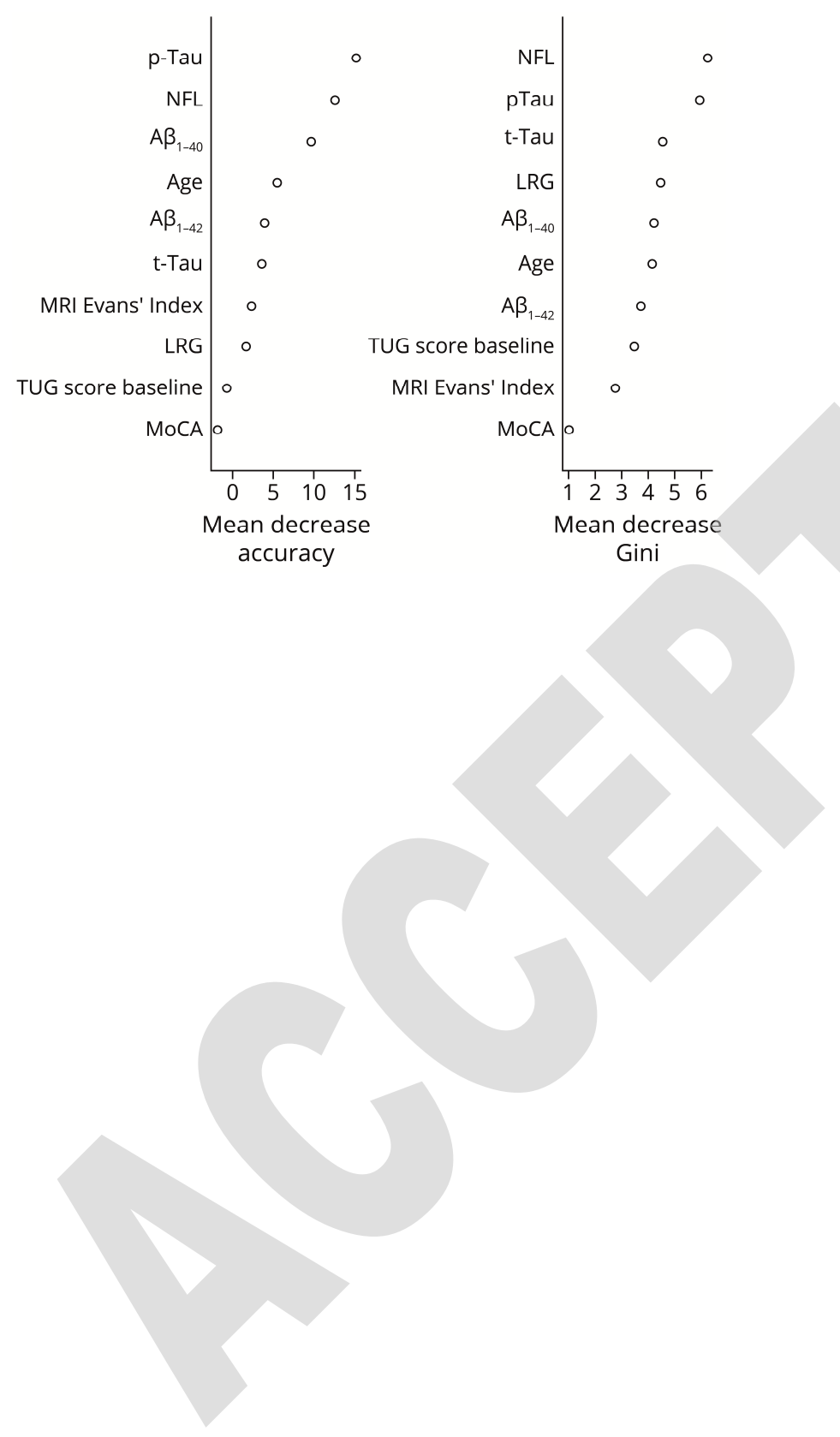




\section{Take Home Points:}

- Several reports have suggested that iNPH represents a predegenerative phase of multiple age-related neurodegenerative disorders presenting with a phenotype involving cognition, gait and bladder control. CSF Biomarkers have been suggested as a means of identifying such confounds and potentially select patients for shunt surgery.

- We show that patients, who do not demonstrate long-term improvement in gait following shunt surgery, have elevations in multiple biomarkers that suggest either comorbid neurodegenerative pathology or advanced brain injury from iNPH itself. Irrespective of the cause of this elevation, analyzing biomarkers in combination can identify who is likely to have a sustained gait response to shunt surgery.

- If replicated in independent cohorts and with longer follow-up, the combination of imaging and CSF biomarkers could potentially refine the selection of iNPH patients for surgery while also facilitating randomized trials of shunt efficacy for this vexing diagnosis. 


\section{Neurology ${ }^{\circ}$ Clinical Practice}

\section{Cerebrospinal Fluid Biomarkers Predict Gait Outcomes in Idiopathic Normal Pressure Hydrocephalus}

Jacqueline A. Darrow, Alexandria Lewis, Seema Gulyani, et al.

Neurol Clin Pract published online January 20, 2022

DOI 10.1212/CPJ.0000000000001156

This information is current as of January 20, 2022

\begin{tabular}{|c|c|}
\hline $\begin{array}{l}\text { Updated Information \& } \\
\text { Services }\end{array}$ & $\begin{array}{l}\text { including high resolution figures, can be found at: } \\
\text { http://cp.neurology.org/content/early/2022/01/19/CPJ.0000000000001156. } \\
\text { ull.html }\end{array}$ \\
\hline Citations & $\begin{array}{l}\text { This article has been cited by } 1 \text { HighWire-hosted articles: } \\
\text { http://cp.neurology.org/content/early/2022/01/19/CPJ.0000000000001156. } \\
\text { ull.html\#\#otherarticles }\end{array}$ \\
\hline Subspecialty Collections & $\begin{array}{l}\text { This article, along with others on similar topics, appears in the following } \\
\text { collection(s): } \\
\text { Cerebrospinal Fluid } \\
\text { http://cp.neurology.org//cgi/collection/cerebrospinal_fluid }\end{array}$ \\
\hline Permissions \& Licensing & $\begin{array}{l}\text { Information about reproducing this article in parts (figures,tables) or in its } \\
\text { entirety can be found online at: } \\
\text { http://cp.neurology.org/misc/about.xhtml\#permissions }\end{array}$ \\
\hline Reprints & $\begin{array}{l}\text { Information about ordering reprints can be found online: } \\
\text { http://cp.neurology.org/misc/addir.xhtml\#reprintsus }\end{array}$ \\
\hline
\end{tabular}

Neurol Clin Pract is an official journal of the American Academy of Neurology. Published continuously since 2011, it is now a bimonthly with 6 issues per year. Copyright Copyright (C) 2022 The Author(s). Published by Wolters Kluwer Health, Inc. on behalf of the American Academy of Neurology.. All rights reserved. Print ISSN: 2163-0402. Online ISSN: 2163-0933.

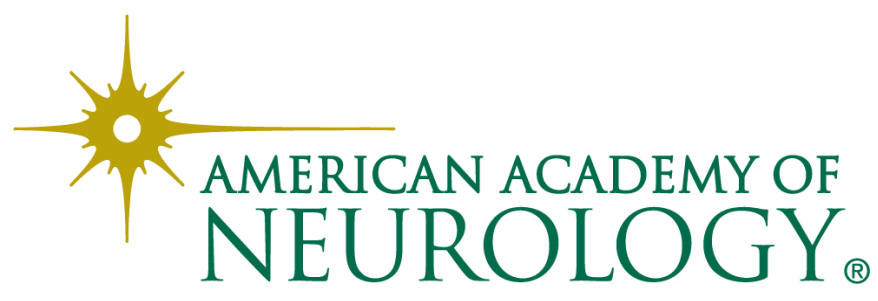

